\title{
Evaluation of DNA ploidy in relation with established prognostic factors in patients with locally advanced (unresectable) or metastatic pancreatic adenocarcinoma: a retrospective analysis
} Nikolas Tsavaris*1, Nicolaos Kavantzas², Kostantinos Tsigritis ${ }^{3}$, Ioannis D Xynos ${ }^{1}$, Nikitas Papadoniou ${ }^{3,9}$, Andreas Lazaris ${ }^{2}$, Christos Kosmas, ${ }^{4}$, George Agrogiannis ${ }^{2}$, Anna Dokou ${ }^{1}$, Evangelos Felekouras ${ }^{3}$, Efstathios Antoniou ${ }^{5}$, Aris Polyzos ${ }^{6}$, John Sarantonis ${ }^{1}$, Heracles Tsipras 7 , Gavrilos Karatzas ${ }^{8}$, Alexandros Papalambros ${ }^{3}$ and Efstratios S Patsouris ${ }^{2}$

Address: ${ }^{1}$ Oncology Unit, Department of Pathophysiology, Laikon General Hospital, Athens University School of Medicine, Athens, Greece, ${ }^{2} 1$ st Department of Pathology, Laikon General Hospital, Athens University School of Medicine, Athens, Greece, ${ }^{3} 1$ st Department of Surgery, Laikon General Hospital, Athens University School of Medicine, Athens, Greece, ${ }^{4}$ 2nd Department of Medical Oncology, Metaxa Cancer Hospital, Piraeus, Greece, ${ }^{5}$ 2nd Department of Surgery-Propedeutic, Laikon General Hospital, Athens University School of Medicine, Athens, Greece, ${ }^{6}$ Oncology Unit, 1st Department of Internal Medicine - Propedeutic, Laikon General Hospital, Athens University School of Medicine, Athens, Greece, 73rd Department of Surgery, "G. Gennimatas" General Hospital, Athens, Greece, ${ }^{8} 3$ rd Department of Surgery, Attiko Hospital, University of Athens School of Medicine, Athens, Greece and ${ }^{9}$ Department of Gastrenterology, "Andreas Papandreou" General Hospital, Rhodes, Greece

Email: Nikolas Tsavaris* - tsavari1@otenet.gr; Nicolaos Kavantzas - nkavantz@med.uoa.gr; Kostantinos Tsigritis - tsigritis@hotmail.com; Ioannis D Xynos - jxynos@hotmail.com; Nikitas Papadoniou - nkladaki@otenet.gr; Andreas Lazaris - alazaris@med.uoa.gr; Christos Kosmas - ckosm1@ath.forthnet.gr; George Agrogiannis - agrojohn@med.uoa.gr; Anna Dokou - annadokou75@yahoo.gr; Evangelos Felekouras - evagekosf@hotmail.com; Efstathios Antoniou - e.a.antoniou@doctors.org.uk; Aris Polyzos - panoraiap@med.uoa.gr; John Sarantonis - ssarantonis@yahoo.gr; Heracles Tsipras - Jimmy123@ath.forthnet.gr; Gavrilos Karatzas - gkaratz@med.uoa.gr; Alexandros Papalambros - stpapalamp@med.uoa.gr; Efstratios S Patsouris - epatsour@med.uoa.gr

* Corresponding author

Published: 31 July 2009

BMC Cancer 2009, 9:264 doi:10.1 186/147/-2407-9-264
Received: 30 January 2009

Accepted: 31 July 2009

This article is available from: http://www.biomedcentral.com/147I-2407/9/264

(c) 2009 Tsavaris et al; licensee BioMed Central Ltd.

This is an Open Access article distributed under the terms of the Creative Commons Attribution License (http://creativecommons.org/licenses/by/2.0), which permits unrestricted use, distribution, and reproduction in any medium, provided the original work is properly cited.

\begin{abstract}
Background: Most patients with ductal pancreatic adenocarcinoma are diagnosed with locally advanced (unresectable) or metastatic disease. The aim of this study was to evaluate the prognostic significance of DNA ploidy in relation with established clinical and laboratory variables in such patients.

Methods: Two hundred and twenty six patients were studied retrospectively. Twenty two potential prognostic variables (demographics, clinical parameters, biochemical markers, treatment modality) were examined.

Results: Mean survival time was 38.4 I weeks ( $95 \%$ c.i.: $33.17-43.65$ ), median survival 27.00 weeks (95\% c.i.: 23.18-30.82). On multivariate analysis, 10 factors had an independent effect on survival: performance status, local extension of tumor, distant metastases, ploidy score, anemia under epoetin therapy, weight loss, pain, steatorrhoea, CEA, and palliative surgery and chemotherapy. Patients managed with palliative surgery and chemotherapy had 6.7 times lower probability of death in comparison with patients without any treatment. Patients with ploidy score $>3.6$ had 5.0 times
\end{abstract}


higher probability of death in comparison with patients with ploidy score $<2.2$ and these with ploidy score $2.2-3.6$ had 6.3 times higher probability of death in comparison with patients with ploidy score $<2.2$.

Conclusion: According to the significance of the examined factor, survival was improved mainly by the combination of surgery and chemotherapy, and the presence of low DNA ploidy score.

\section{Background}

Carcinoma of the pancreas is a very aggressive tumor, posing the fourth leading cause of cancer-related death in the United States [1,2]. Most patients with pancreatic ductal adenocarcinoma present with locally advanced or metastatic disease on diagnosis, despite the availability of advanced imaging techniques. Only 10-20\% of cases are candidates for curative surgery [3-5] and in these cases, the reported 5-year survival rate ranges between $11 \%$ and $25 \%$ [6-8] as persistence or recurrence of regional disease is reported in approximately $80 \%$ of patients following curative resection [9]. Subsequently, surgery for pancreatic cancer plays frequently a palliative role, to cure jaundice, obstruction or pain [10]. Surgical palliation on the other hand appears to be associated with a higher rate of early complications and possibly a higher rate of procedure related mortality [11], while stents may become obstructed causing recurrent jaundice [12].

To improve the prognosis of patients with pancreatic cancer, it is essential to provide non-surgical treatment options, such as systemic chemotherapy or targeted therapy [13]. Systemic chemotherapy for pancreatic cancer has proven of limited value because of the low response rates and the severe adverse effects. Patients suitable for chemotherapy should, therefore, be carefully selected on the basis of specific prognostic factors. Several studies have reported various pre- and postoperative factors as determinants of short- and long-term survival in patients undergoing surgery, but little is known about prognostic indices for survival in patients with unresectable disease [14-26].

The influence of DNA content on prognosis in adenocarcinomas of the pancreas has been investigated occasionally, and the results are controversial. The findings published in the literature, suggest that additional studies are required to obtain the prognostic impact of DNA content in pancreatic cancer [27].

In a previously published study by our group we have identified a number of factors which had independent impact on survival including tumor localization, metastases, PS, jaundice, weight loss, CRP, raised CEA and CA19.9, palliative surgery and chemotherapy [28]. In the present study we update our patient cohort with the addition of a new laboratory parameter, DNA content.

\section{Methods \\ Patients and data sources}

The medical records of 226 patients between 1997 and 2003, with a histological diagnosis of pancreatic adenocarcinoma, from five Greek general hospitals were retrospectively reviewed. All had advanced unresectable pancreatic adenocarcinoma. For the diagnosis of distant metastasis, various imaging modalities were used, including chest X-ray, ultrasonography and computed tomography. Pathological confirmation of ductal adenocarcinoma was obtained by surgery or a fine-needle aspiration biopsy (FNAB). Survival time was calculated from time of diagnosis to death due to pancreatic cancer-related complications. Records with complete data (for the parameters used as prognostic factors) were included in the analysis. This protocol has been approved (ID:6443, 15/03/2004) by the National and Kapodistrian University of Athens human research ethics committee.

\section{Prognostic variables}

Twenty-two possible prognostic variables were selected, based on factors identified by previous studies [6-8,1426,28 ] (Table 1). Histopathological grading was based on the WHO system [29]. Patients were staged according to the International Union Against Cancer TNM classification [30].

For the evaluation of continuous biochemical parameters we used group categorisations: for C-reactive protein (CRP) normal <5 mg/dL, elevated: $5-15 \mathrm{mg} / \mathrm{dL},>15 \mathrm{mg} /$ dL); for cancer antigen 19-9 (CA 19-9); patients with values $\leq 30 \times \mathrm{nl}$ vs $>30 \times \mathrm{nl}$; for carcinoembryonic antigen (CEA) normal $\leq 5 \mathrm{mg} / \mathrm{dL}$ and elevated $>5 \mathrm{mg} / \mathrm{dL}$; for amylase: yes and no; for hypoalbuminaemia: yes and no; for diabetes: yes and no. Anemia, before initiation of any therapy, was presented in two groups; severe (patients received blood transfusion), and moderate (patients received therapy with epoetin). For clinical parameters similar categorisations were used. For therapy: palliative surgery followed by chemotherapy, surgery only, chemotherapy only, supportive care only; for performance status (PS): $\geq 90,=80,=70,=60$ and $\leq 50$; for jaundice: $y e s$ and no; for thrombophlebitis: yes and no; for steatorrhoea: yes and no; for weight loss: none, $1-5 \%, 6-10 \%$ and $>10 \%$ of the total body weight. Pain was graded as follows: grade 0 : absence of pain, grade 1: palliation with common analgesics (paracetamol, NSAIDs), grade 2: controlled with the 
Table I: Demographic and clinical variables in the study population $(n=226)$

\begin{tabular}{|c|c|c|c|}
\hline Variable & Labels & $\mathbf{n}$ & $\%$ \\
\hline \multirow[t]{2}{*}{ Gender } & Males & 132 & 61.4 \\
\hline & Females & 83 & 38.6 \\
\hline \multirow[t]{2}{*}{ Age } & $\leq 60$ & 87 & 40.5 \\
\hline & $60+$ & 128 & 59.5 \\
\hline \multirow[t]{5}{*}{ PS } & $\geq 90$ & 25 & 11.1 \\
\hline & $=80$ & 75 & 33.2 \\
\hline & $=70$ & 74 & 19.5 \\
\hline & $=60$ & 40 & 17.7 \\
\hline & $\leq 50$ & 42 & 18.6 \\
\hline \multirow[t]{3}{*}{ Location } & Head & 147 & 68.4 \\
\hline & Body & 52 & 24.2 \\
\hline & Back ('tail") & 16 & 7.4 \\
\hline \multirow[t]{4}{*}{ Therapy } & Chemotherapy and surgery & 53 & 24.7 \\
\hline & Chemotherapy only & 65 & 30.2 \\
\hline & Surgery only & 24 & 11.2 \\
\hline & None & 73 & 34.0 \\
\hline \multirow[t]{2}{*}{ Surgery } & Yes & 77 & 35.8 \\
\hline & No & 138 & 64.2 \\
\hline \multirow[t]{2}{*}{ Chemotherapy } & Yes & 118 & 54.9 \\
\hline & No & 97 & 45.1 \\
\hline \multirow[t]{3}{*}{ Ploidy } & $<2.2$ & 20 & 8.8 \\
\hline & $2.2-3.6$ & 86 & 38.1 \\
\hline & $>3.6$ & 120 & 53.1 \\
\hline \multirow[t]{2}{*}{ Amylase } & Yes & 23 & 10.7 \\
\hline & No & 192 & 89.3 \\
\hline \multirow[t]{3}{*}{ Grading } & High & 14 & 6.5 \\
\hline & Medium & 187 & 87.0 \\
\hline & Low & 14 & 6.5 \\
\hline \multirow[t]{4}{*}{ Primary tumor extent } & I & 15 & 7.0 \\
\hline & 2 & 60 & 27.9 \\
\hline & 3 & 77 & 35.8 \\
\hline & 4 & 63 & 29.3 \\
\hline \multirow[t]{2}{*}{ CEA } & $\leq 5 \mathrm{mg} / \mathrm{dL}$ & 72 & 33.5 \\
\hline & $>5 \mathrm{mg} / \mathrm{dL}$ & 143 & 66.5 \\
\hline \multirow[t]{2}{*}{ CA $19-9$} & $\leq 30 \times$ normal & 30 & 14.0 \\
\hline & $>30 \times$ normal & 185 & 86.0 \\
\hline \multirow[t]{2}{*}{ Thrombophlebitis } & Yes & 105 & 48.8 \\
\hline & No & 110 & 51.2 \\
\hline \multirow[t]{2}{*}{ Diabetes } & Yes & 199 & 92.6 \\
\hline & No & 16 & 7.4 \\
\hline \multirow[t]{3}{*}{ CRP } & Normal & 150 & 69.8 \\
\hline & Increased & 35 & 16.3 \\
\hline & Greatly increased & 30 & 14.0 \\
\hline \multirow[t]{2}{*}{ Steatorrhoea } & Yes & 99 & 46.0 \\
\hline & No & 116 & 54.0 \\
\hline \multirow[t]{2}{*}{ Albumin } & Yes & 114 & 53.0 \\
\hline & No & 101 & 47.0 \\
\hline Epoetin & Yes & 36 & 16.7 \\
\hline & No & 179 & 83.3 \\
\hline Transfusion & Yes & 61 & 28.4 \\
\hline & No & 154 & 71.6 \\
\hline Weight loss & None & 62 & 28.8 \\
\hline & $\mid-5 \%$ & 31 & 14.4 \\
\hline & $6-10 \%$ & 58 & 27.0 \\
\hline & $>10 \%$ & 64 & 29.8 \\
\hline Pain & None & 50 & 23.3 \\
\hline & Pain I & 84 & 39.1 \\
\hline & Pain 2 & 55 & 25.6 \\
\hline
\end{tabular}

Table I: Demographic and clinical variables in the study population $(\mathbf{n}=\mathbf{2 2 6})$ (Continued)

\begin{tabular}{llrr}
\hline \multirow{3}{*}{ Metastases } & Pain 3 & 26 & 12.1 \\
& None & 86 & 40.0 \\
& LN & 37 & 17.2 \\
& LIV & 7 & 3.3 \\
& AB & 29 & 13.5 \\
LN-AB & 30 & 14.0 \\
Jaundice & LIV-LN-AB & 26 & 12.1 \\
& Yes & 46 & 21.4 \\
& No & 169 & 78.6
\end{tabular}

$A B$, abdominal metastasis; $C A$ 19-9, cancer antigen 19-9; CEA, carcinoembryonic antigen; CRP, C-reactive protein; LIV, liver metastasis; LN, lymph node metastasis; I: tumor $<2 \mathrm{~cm}$ confined to the panreas, 2: tumor $>2 \mathrm{~cm}$ confined to the pancreas, 3 : invasion of adjacent tissues by tumor, 4 : invasion of adjacent organs.

use of opioids (fentanyl or morphine), grade 3: does not remit completely despite the use of opioid analgesics. For location of cancer: head, body and back (tail) of pancreas; for primary tumor extent: tumor $<2 \mathrm{~cm}$ confined to the pancreas, tumor $>2 \mathrm{~cm}$ confined to the pancreas, invasion of adjacent tissues by tumor, invasion of adjacent organs and for distant metastasis: yes and no. For ploidy score, group categorisation was also applied: $<2.2,2.2-3.6,>3.6$.

\section{DNA Measurements (Ploidy)}

The nuclei of Feulgen-stained cells were evaluated for DNA ploidy using a Nikon eclipse microscope (Nikon, Japan) connected with a Nikon CCD videocamera and an IBM Pentium 4/PC with the appropriate Cell Measurement Software (Image Pro Plus v. 5.1, Media Cybernetics Inc, Silver Springs, MD, USA). A total of 100-200 nuclei with clear boundaries appearing to have no loss of membrane integrity were identified for analysis from each tissue sample. Measurements were made using a magnification of $\times 200$. This analysis configuration permits operator-dependent selection and measurement of DNA content (Figures 1 and 2). This cell measurement system was calibrated before each analysis session using a slide with human normal lymphocytes with known DNA content. The data generated were downloaded to standard software packages for final analysis. DNA histograms were categorized as diploid if the histogram presented a single peak (2c; c = haploid DNA content) in the G0-G1 area and the cell nuclei population did not exceed $10 \%$ in the G2 region (4c). A sample was considered aneuploid if clear aneuploid peaks ( $3 c, 5 c, 7 c$ and $9 c)$ were present. For each case, coefficient of variance (CV) and DNA index/ ploidy score was calculated relative to internal controls (lymphocytes; DI $=0.1$ ) A ploidy score between 0.9 and 1.1 was considered diploid, aneuploid 1.1-1.4, triploid 1.4-1.8, tetraploid 1.8-2.2, hypertetraploid $>2,2$.

\section{Statistical analysis}

Descriptive statistics are calculated with the measures of means, medians and standard deviation for quantitative 
parameters and counts/percentages for discrete factors. Overall survival is studied with the use of Kaplan Meier method. Survival differences between groups are studied with the use of Log-rank test. A Multivariate Cox regression model was implemented to study the simultaneous effect of parameters on survival after taking into account the parallel effect of remaining factors. Best model selection was based on manual and automated forward techniques. Results of regression analyses are displayed in the form of regression estimates tables. Hazard ratios of outcomes under study are calculated for each parameter estimate as well as 95\% confidence intervals. Categorical covariates are compared with a predefined reference category.

All analyses are performed at a significance level of $\alpha=$ 0.05 with the use of the statistical package SPSS 12.0.

\section{Results \\ Patients}

Two hundred and twenty six records of patients with histologicaly confirmed pancreatic carcinoma entered the analysis. Their Median age was 62.5 years (range 32-76, median 63.0 and standard deviation: 7.76 years) and the Median PS (Karnofsky) was 70 (range 40-100). Palliative surgery was performed in $52.7 \%$ of patients, while $62.9 \%$ received chemotherapy for advanced disease. The frequencies of the clinical variables are shown in Table 1.

Despite the fact that authors included in the present study derived from 5 different institutions, it should be stressed- out that all patients during the study period were treated by General Surgeons derived from "Laikon" General Hospital, and all three Medical Oncologists participating in the present study were again affiliated at the same institution (except C.K. who joined "Metaxa" Cancer Hospital after October 2001), and more importantly applied the same therapeutic protocols/algorithms. These treatment algorithms evolved over time in accordance to internationally accepted standards and guidelines with respect to advanced pancreatic cancer. From 1997-2000 a combination of 5FU-Leucovorin (LV)-Epirubicin-Mitomycin (FEMLV) was applied at $1^{\text {st }}$-line followed by single-agent Gemcitabine or the combination of Gemcitabine/CPT11

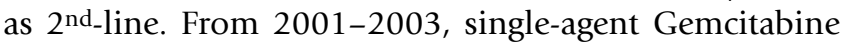

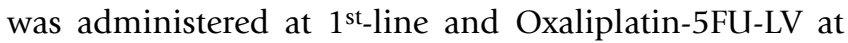

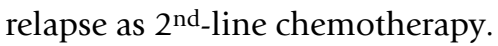

\section{Survival analysis}

Survival data were collected for all patients. Four patients were alive at the end of the study, and their survival time was censored. Based on Kaplan-Meier method, mean survival time was recorded at 38.41 weeks (95\% c.i.: 33.1743.65), median survival: 27.00 weeks (95\% c.i.: $23.18-$ 30.82).

\section{Univariate analysis}

In the univariate analysis, all variables were related to the survival outcome at a significance level of alpha $=10 \%$, apart from gender, age and CA19-9 (Table 2).

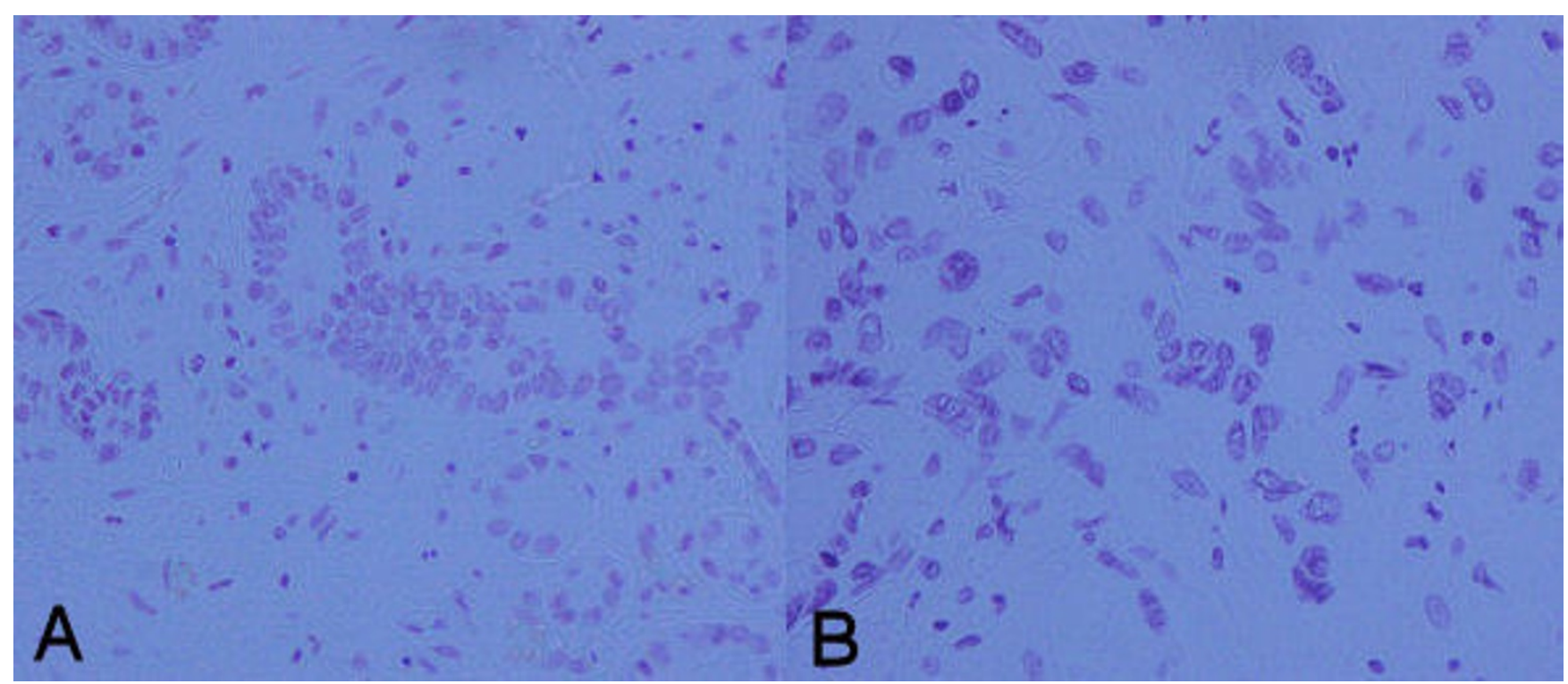

Figure I

DNA index I.9 (A) versus DNA index 4.4 (B) as derived by subsequent image analysis of pancreatic tumor specimens (Feulgen staining, 200x). 


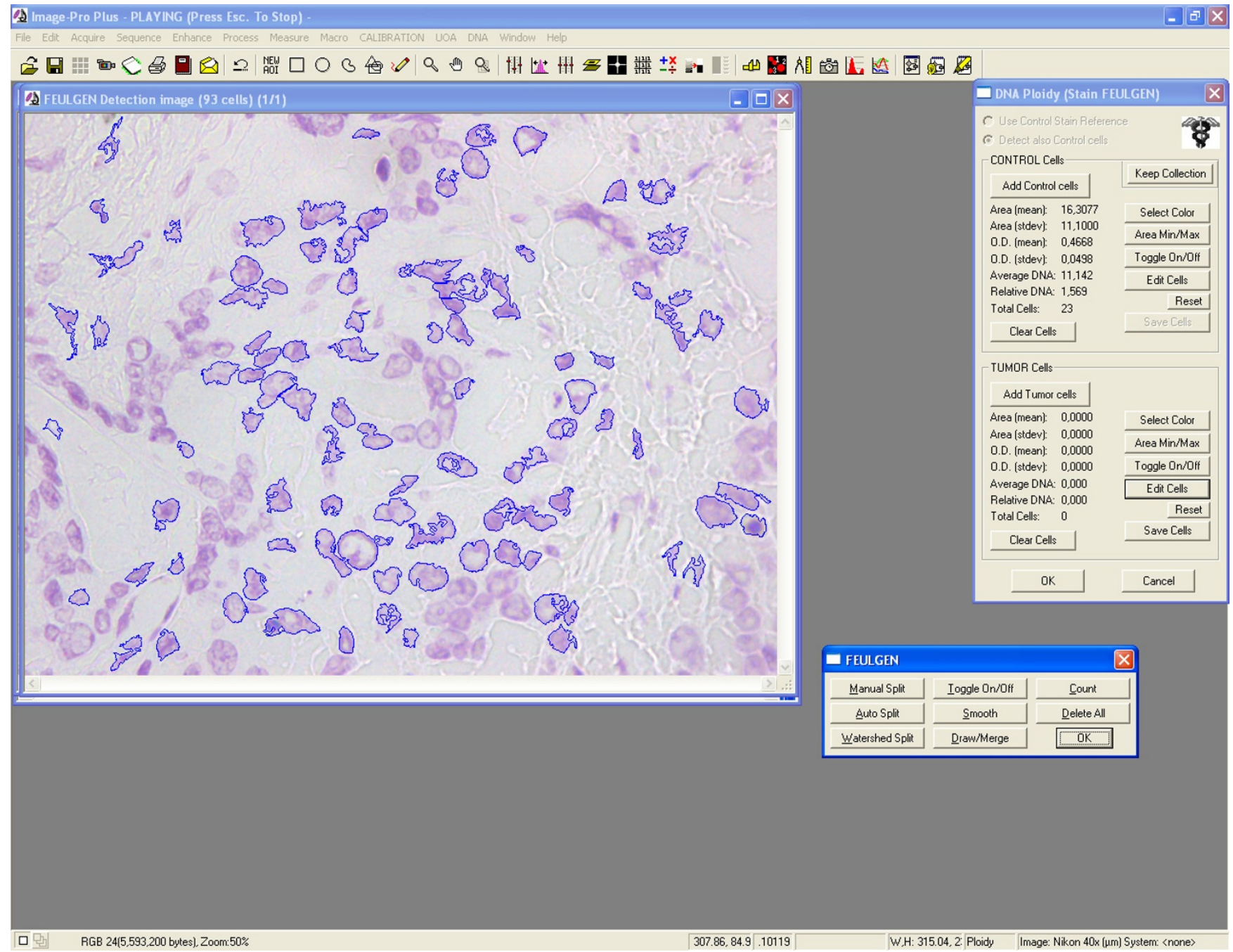

Figure 2

Representative snapshot from image analysis screen (DNA ploidy). Nuclei are semiautomatically circumscribed and measured.

\section{Multivariate analysis}

Prognostic factors found to have strongest significance of a relation to survival according to the univariate analysis were entered into the multivariate analysis model first (Table 3). Factors were added and excluded using the change in likelihood between models as inclusion and exclusion criteria. Both manual and forward automated procedures resulted in the same final model, which is described in Table 3.

\section{Hazard ratios of risk factors}

Patients with PS 80 had 3.0 times lower probability of death in comparison with patients with PS 50, and patients with PS 90 had 3.9 times lower probability of death in comparison with patients with PS 50. Patients with distant metastases in lymph nodes, liver or the abdo- men had 2.5 times higher probability of death in comparison with patients without. Patients at local extension of the tumor stage 2 had 2.8 times higher probability of death in comparison with patients at stage 1 . Patients with with moderate anaemia under epoetin therapy had 1.5 times lower probability of death in comparison with patients without. Patients with weight loss $1-5 \%$ or $5-$ $10 \%$ of body weight had 3.0 times lower probability of death in comparison with patients with weight loss > $10 \%$. Patients with steatorrhoea had 1.8 times higher probability of death in comparison with patients without. Patients with CEA > $5 \mathrm{mg} / \mathrm{dL}$ had 1.4 times higher probability of death in comparison with patients with CEA $<5$ $\mathrm{mg} / \mathrm{dL}$. Patients with moderate pain had 2.1 times lower probability of death in comparison with patients with severe pain. Patients with ploidy score $2.2-3.6$ had 6.3 
Table 2: Univariate analysis of survival time by categorical variable

\begin{tabular}{llll}
\hline Parameter & $\begin{array}{l}\text { Log-rank } \\
\text { Test value }\end{array}$ & Degrees of Freedom \\
\hline Gender & 1,79 & 1 & 0,1811 \\
Age (years) & 0,34 & 1 & 0,5586 \\
PS & 229,07 & 4 & $<0.001$ \\
Location & 10,60 & 2 & $<0.005$ \\
Grading & 15,22 & 2 & $<0.005$ \\
Primary tumor extent & 40,90 & 3 & $<0.001$ \\
Distant Metastasis & 38,80 & 1 & $<0.001$ \\
Ploidy-group & 93,79 & 2 & $<0.001$ \\
Epoetin & 9,16 & 1 & 0.003 \\
Blood Transfusion & 22,64 & 1 & $<0.001$ \\
Weight loss & 178,78 & 3 & $<0.001$ \\
Pain & 79,81 & 3 & $<0.001$ \\
Jaundice & 6,49 & 1 & 0.01 \\
Thrombophlebitis & 16,87 & 1 & $<0.001$ \\
Diabetes & 4,36 & 1 & 0.04 \\
Steatorrhoea & 37,96 & 1 & $<0.001$ \\
CEA & 37,51 & 1 & 0.001 \\
CA I99 & 1,13 & 1 & $<0.001$ \\
Amylase & 6,43 & 1 & 0.01 \\
CRP & 6,95 & 2 & $<.03$ \\
Albumin & 54,78 & 1 & $<0.001$ \\
Therapy & 161,48 & 3 & $<0.001$ \\
\end{tabular}

PS: Performance Status; CEA, carcinoembryonic antigen; CA 19-9, cancer antigen 19-9; CRP, C-reactive protein.

times higher probability of death in comparison with patients with ploidy score $<2$.2. Patients with ploidy score $>3.6$ had 5.0 times higher probability of death in comparison with patients with ploidy score $<2.2$ (Figure 3 ). Patients with only chemotherapy had 4.2 times lower probability of death in comparison with patients without any treatment. Patients with chemotherapy and surgery had 6.7 times lower probability of death in comparison with patients without any treatment (Figure 4).

\section{Discussion}

The majority of patients with pancreatic cancer are not eligible for surgery at presentation because the disease only becomes symptomatic at late stages. Therefore, predictive factors for patients presenting with unresectable, locally recurrent or metastatic disease should be considered when selecting appropriate treatment for each individual patient $[6,21-23,25]$.

The prognostic value of DNA ploidy in pancreatic carcinoma has been studied in the past and results have been disappointing [27]. The first reported evaluation of DNA nuclear pattern in pancreatic cancer was in 1987 by Weger et al who used flow cytometry to examine 77 cases of ductal carcinoma [31]. There were no diploid tumor tumors and all patients $(\mathrm{n}=16)$ with triploid neoplasms died within 18 months. In contrast, of 15 patients with near tetraploid tumors, 8 were alive at 70 months after the time of diagnosis. Since then, a number of studies have reported conflicting results in terms of prognostic value of these techniques in pancreatic cancer. Bottger $e t$ al examined DNA content in 41 cases following resection using image cytometry [32].

Hypotriploid ( $\mathrm{n}=1)$, triploid $(\mathrm{n}=7)$, hypertriploid ( $\mathrm{n}=$ $21)$, and tetraploid $(\mathrm{n}=12)$ patterns were noted. Tetraploid tumors had a significantly improved survival versus non-tetraploid tumors $(\mathrm{p}=0.0037)$. They found that DNA ploidy was the strongest independent prognostic factor for survival in these patients by multivariate analysis. Yeo et al determined DNA content by image cytometry and found that $43 \%$ of 119 tumors were diploid and $57 \%$ were aneuploid. Patients with diploid tumors had a median survival of 24 months and 5-year survival of 39\%, significantly better than the median survival of 11.5 months and 5-year survival of $8 \%$ observed in patients with aneuploid tumors; $\mathrm{p}=0.0002$. In multivariate analysis DNA content was one of the strongest independent predictors of favourable outcome in pancreatic cancer [33]. Porschen et al determined DNA content by flow cytometry and found that 29 of 56 (52\%) pancreatic ductal adenocarcinomas were diploid, while 27 (48\%) were aneuploid. The median survival of those with diploid tumors was 6.9 months as compared to 4.5 months for aneuploid tumors $(\mathrm{p}=0.013)$, but this survival benefit was seen mostly in patients who underwent nonradical surgical intervention. In multivariate analysis, the only factors associated with survival were radicality of surgery 
Table 3: Final Cox proportional odds regression model

\begin{tabular}{|c|c|c|c|c|c|c|c|}
\hline \multirow[t]{2}{*}{ Variable } & \multirow[t]{2}{*}{ B } & \multirow[t]{2}{*}{ SE } & \multirow[t]{2}{*}{ Wald } & \multirow[t]{2}{*}{$\mathbf{p}$} & \multirow[t]{2}{*}{ Hazard ratio } & \multicolumn{2}{|c|}{$95,0 \% \mathrm{Cl}$ for $\operatorname{Exp}(\mathrm{B})$} \\
\hline & & & & & & Lower & Upper \\
\hline $\mathrm{PS}(60$ vs $\leq 50)$ & ,376 & ,268 & 1,966 &, 161 & 1,456 & ,861 & $2,46 I$ \\
\hline $\mathrm{PS}(70$ vs $\leq 50)$ &,- 501 & 319 & 2,467 &, 116 &, 606 & 324 & 1,132 \\
\hline $\mathrm{PS}(80$ vs $\leq 50)$ & $-1,180$ & 345 & 11,676 & 001 & ,307 & 156 &, 605 \\
\hline $\mathrm{PS}(90$ vs $\leq 50)$ & $-1,357$ & 420 & 10,437 & 001 & ,257 &, 113 & ,586 \\
\hline PRIMARY EXTENT(4 vs I) &, 085 & ,489 & 030 & 862 & 1,088 &, 418 & 2,836 \\
\hline PRIMARY EXTENT (3 vs I) & 399 & ,495 & 649 & 420 & $|, 49|$ &, 564 & 3,936 \\
\hline PRIMARY EXTENT (2 vs I) & 1,015 &, 518 & 3,838 & 050 & 2,758 & 1,000 & 7,610 \\
\hline DISTANT METASTASES (yes vs no) & 949 & 247 & 14,730 &, 000 & 2,583 & $1,59 \mid$ & 4,194 \\
\hline PLOIDY $(3.6+$ vs <2.2) & 1,605 & ,34l & 22,093 &, 000 & 4,975 & 2,548 & 9,714 \\
\hline PLOIDY $(2.2-3.6$ vs <2.2) & 1,846 &, 375 & 24,251 &, 000 & 6,333 & 3,038 & $13,20 \mid$ \\
\hline EPOETIN - ANEMIA (yes vs no) &,- 441 &, 184 & 5,779 &, 016 & 643 & ,449 & ,922 \\
\hline WEIGHT LOSS (none vs I0+) &,- 536 & ,379 & 1,997 &, 158 &, 585 & ,278 & 1,230 \\
\hline WEIGHT LOSS (I-5\% vs I0+) & $-1,081$ &, 330 & 10,719 &, 001 & 339 & 178 & ,648 \\
\hline WEIGHT LOSS (5-10\% vs I0+) & $-1,097$ &, 268 & 16,756 & 000 & ,334 & 197 &, 565 \\
\hline PAIN (none vs severe) &,- 360 & ,355 & $\mathrm{I}, 028$ & 311 & 698 & ,348 & 1,399 \\
\hline PAIN (light vs severe) &,- 224 & ,286 & 613 & ,434 & ,799 & ,456 & 1,400 \\
\hline PAIN (moderate vs severe) &,- 769 & ,281 & 7,486 & 006 & ,463 & ,267 & ,804 \\
\hline STEATORIA (yes vs no) &, 585 &, 183 & 10,185 &, 001 & $\mathrm{I}, 795$ & 1,253 & 2,572 \\
\hline CEA $(>5$ vs $<=5)$ & ,345 &, 161 & 4,586 & 032 & 1,413 & 1,030 & 1,938 \\
\hline THERAPY (CT vs none) & $-1,449$ & ,272 & 28,445 &, 000 & 235 &, 138 & ,400 \\
\hline THERAPY (Surgery vs none) &,- 416 &, 254 & 2,669 & 102 & 660 & ,401 & 1,087 \\
\hline THERAPY(both vs none) & $-1,903$ &, 270 & 49,641 &, 000 & 149 & ,088 &, 253 \\
\hline
\end{tabular}

PS, Performance Status; CEA, carcinoembryonic antigen; CT, Chemotherapy.

and DNA ploidy. The authors concluded that DNA ploidy adds valuable information which is distinct from other clinico-pathological variables [34]. Similar results have been reported by others [35-39]. In contrast, Baisch et al using flow cytometry analysis did not find DNA ploidy to be a prognostic factor for survival [40]. They did note that aneuploidy $(15 \%)$ of their cases was associate with advanced stage and tended to be more common in high grade tumors. Herrera et al examined a cohort of 72 patients who underwent radical resection at the Mayo Clinic between 1951 and 1980 [41]. The patients with short (mortality within 12 months) and long term survival ( $>3$ years) were examined. No difference in the DNA nuclear histograms, the fraction of cells in the S phase or DNA index was noted between these two groups. Similarly, in a recently published study, Stoecklein et al reported their results of DNA ploidy in conjunction to HER2 amplification and chromosome 17 copy number analysis in patients with pancreatic ductal adenocarcinoma after radical operation (R0 resection). Tumor ploidy levels correlated with prognosis of patients with pancreatic ductal adenocarcinoma, in contrast, to the absence of a prognostic effect on patient outcome regarding HER2 gene amplification or p185 (HER2) overexpression [42]. Berczi et al also concluded using flow cytometry analysis that DNA ploidy status had no significant effect on survival of patients with carcinoma of the pancreatic head region [43]. To some extend, disparate results in DNA ploidy studies have been ascribed to the differing techniques employed, and the heterogeneity in the nuclear DNA content in pancreatic tumor cells, hence image cytometry has generally been considered superior to flow cytometry as only tumor cells are used for DNA measurement [34]. Subsequently, the clinical utility of DNA ploidy has been limited and its role in staging and treatment is still under investigation [27].

In the present study all factors under investigation were significantly related to survival time except gender, age, and CA-19.9, which is largely in accordance with results 


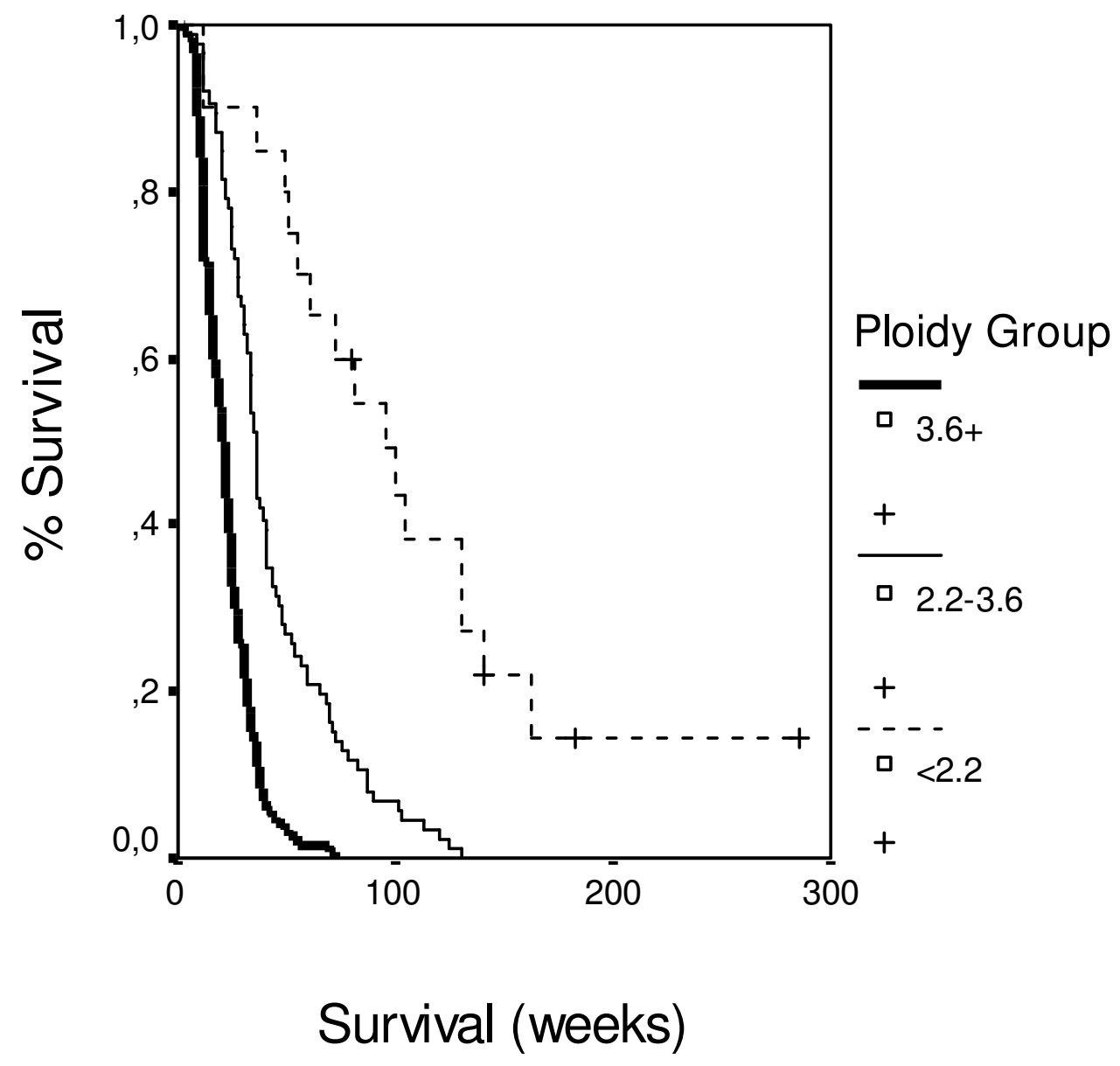

Figure 3

Survival data according to tumor ploidy.

previously published by our group and others [28]. We distinguished three groups of factors that influence survival. The first group of factors relates to the presence of disease. Patients with distant metastasis and/or locally extensive disease had a worse prognosis. Patients with increased ploidy score and/or increased levels of the marker CEA, which represent increased tumor burden, were also associated with a worse prognosis. The second group of factors relates to the clinical characteristics of the patient and the immune response such as poor PS at the time of diagnosis, weight loss, severity of pain, steatorrhoea, and anaemia under epoetin-A therapy. Each of these factors was related to a negative influence on survival. The third group of factors relates to therapeutic modalities: patients given only supportive care had the worst survival in comparison to those who underwent chemotherapy and better with the combination of chemotherapy and surgery.

According to the significance of the examined factor, survival was improved mainly by the combination of surgery and chemotherapy, and by a low DNA ploidy score. Secondary factors are the performance status (performance status and weight loss) and expansion of cancer (local extension and distant metastases). Considerable factors are pain, anemia, steatorrhoea, and CEA value.

The present study represents a comprehensive analysis regarding the prognostic significance of microscopically assessed DNA ploidy in the context of additional patientand treatment-related known prognostic factors in a large cohort of advanced inoperable ductal pancreatic adenocarcinoma. Our analysis demonstrated that DNA ploidy, 


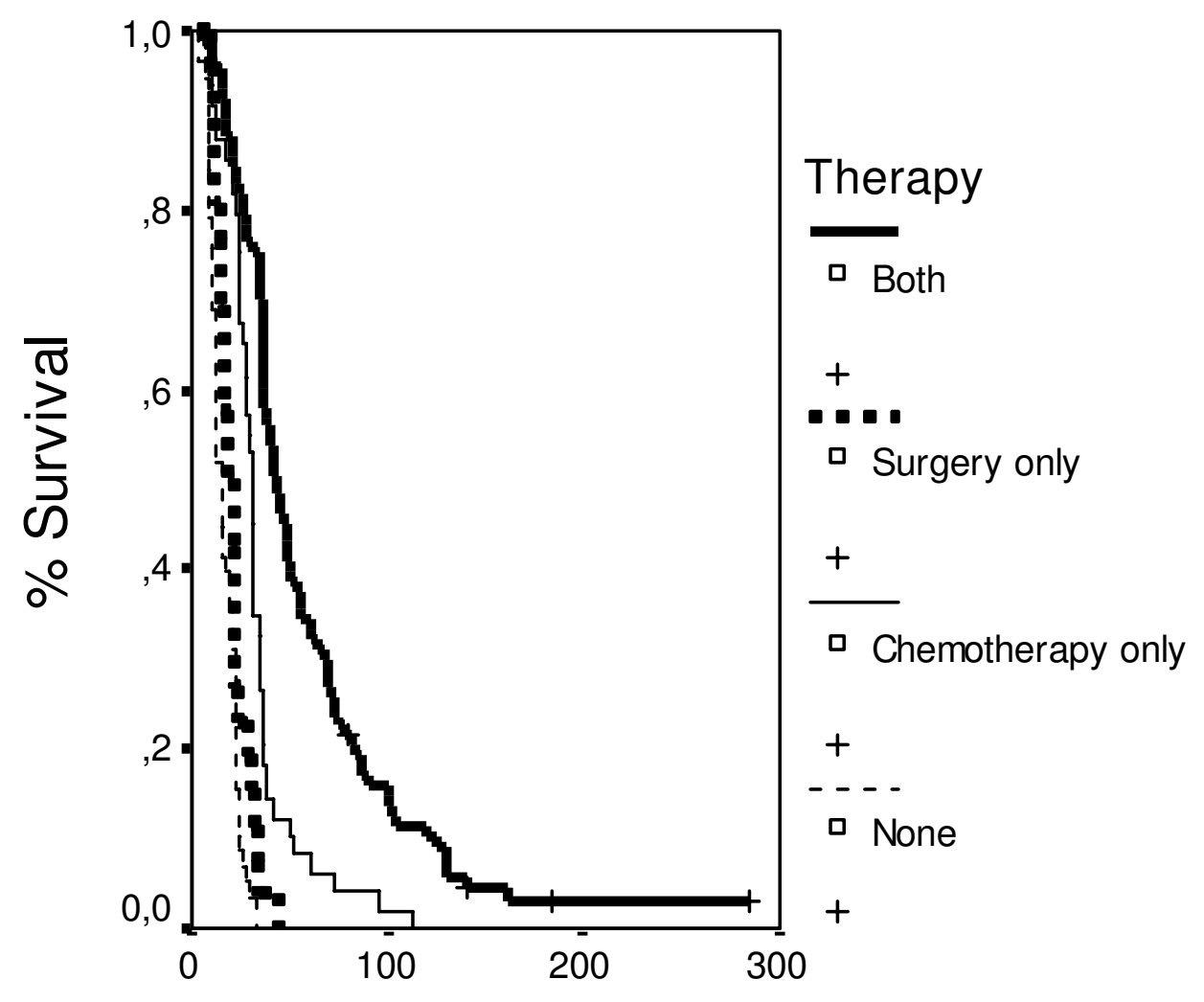

\section{Survival (weeks)}

Figure 4

Survival data according to therapy.

together with chemotherapy or surgery or surgery plus chemotherapy carry the most significant independent effect on outcome of advanced pancreatic adenocarcinoma.

\section{Conclusion}

In conclusion, we assessed factors that are related to the outcome of patients with advanced, unresectable ductal pancreatic adenocarcinoma. The determination of DNA content of pancreatic cancer cells provides additional prognostic information and should be considered along with other established prognostic factors for the development of effective multidisciplinary treatment strategies and the design of future clinical trials. In terms of treatment modality our study reinforces the notion that the main factor, which may affect survival in patients with pancreatic cancer is therapy, and so all patients, unless contraindicated, should be offered palliative surgery and chemotherapy, or chemotherapy alone if the tumor is considered unresectable.

\section{Competing interests}

The authors declare that they have no competing interests.

\section{Authors' contributions}

NT conceived of the study, and participated in its design and coordination and helped to draft the manuscript. NK, AL participated in study design and laboratory work. KT participated in study design, collection of the data and laboratory work. IDX and CK were involved in data interpretation, critical review and helped to draft the manuscript. NP, AD, AP and JS participated in the collection of clinical data (clinical oncology). GA: performed part of laboratory work and was involved in the collection of laboratory data. EF, EA, HT and GK participated in the collection of clinical data (surgical oncology). EP coordinated 
the collection of clinical data (surgical oncology). ESP coordinated the collection of laboratory data. All authors read and approved the final manuscript.

\section{Acknowledgements}

We thank Madalena Zlovotska for data collection and Mr Dimitrios Boulamatsis for performing the statistical tests. This trial was supported by grant of ELKE 80546 of the University of Athens School of Medicine.

\section{References}

I. Jemal A, Murray T, Ward E, Samuels A, Tiwari RC, Ghafoor A, Feuer EJ, Thun MJ: Cancer statistics, 2005. CA Cancer J Clin 2005, 55:10-30.

2. Anderson KE, Potter JD, Mack TM: Pancreatic cancer. In Cancer Epidemiology and prevention Edited by: Schottenfeld D, Fraumeni JF Jr. New York: Oxford University Press; 2005:725-77I.

3. Niederhuber JE, Brennan MF, Menck HR: The National Cancer Data Base Report on pancreatic cancer. Cancer 1995, 76:167|-1677

4. Reber HA, Gloor B: Radical pancreatectomy. Surg Oncol Clin North Am 1998, 7:157-163.

5. Fong Y, Blumgart LH, Fortner JG, Brennan MF: Pancreatic or liver resection for malignancy is safe and effective for the elderly. Ann Surg 1995, 222:426-437.

6. Yeo CJ, Cameron JL, Sohn TA, Lillemoe KD, Pitt HA, Talamini MA, Hruban RH, Ord SE, Sauter PK, Coleman J, Zahurak ML, Grochow LB, Abrams RA: Six hundred fifty consecutive pancreaticoduodenectomies in the 1990s: pathology, complications, and outcomes. Ann Surg 1997, 226:248-60.

7. Conlon KC, Klimstra DS, Brennan MF: Long-term survival after curative resection for pancreatic ductal adenocarcinoma. Clinicopathologic analysis of 5-year survivors. Ann Surg 1996, 223:273-279.

8. Sperti C, Pasquali C, Piccoli A, Pedrazzoli S: Survival after resection for ductal adenocarcinoma of the pancreas. $\mathrm{Br}$ J Surg 1996, 83:625-631.

9. Magistrelli P, Antinori A, Crucitti A, Le Greca A, Masetti R, Coppola R, Nuzzo G, Picciocchi A: Prognostic factors after surgical resection for pancreatic carcinoma. / Surg Oncol 2000, 74:36-40.

10. Matsuno S, Egawa S, Shibuya K, Shimamura H, Sunamura M, Takeda K, Katoh H, Okada S, Suda K, Nakao A, Isaji S, Hiraoka T, Hosotani $R$, Imaizumi T: Pancreatic cancer: current status of treatment and survival of $|607|$ patients diagnosed from I98 I-using the Japanese National Pancreatic Cancer Database. Int J Clin Oncol 1996, 5: I53-157.

II. Smith AC, Dowsett JF, Russell RC, Hatfield AR, Cotton RB: Randomised trial of endoscopic stending versus surgical bypass in malignant low bileduct obstruction. Lancet 1994, 344:1655-1660.

12. Lillemoe KD, Pitt HA: Palliation. Surgical and otherwise. Cancer 1996, 78(3 Suppl):605-I4.

13. Link KH, Gansauge F, Goerich J, Leder G, Rillinger N, Berger HG Palliative and adjuvant regional chemotherapy in pancreatic cancer. Eur J Surg Oncol 1997, 23:409-4I4.

14. Kalser MH, Barkin J, Maclntyre JM: Pancreatic cancer. Assessment of prognosis by clinical presentation. Cancer 1985, 56:397-402.

15. Falconer JS, Fearon KC, Ross JA, Elton R, Wigmore SJ, Garden OJ, Carter DC: Acute-phase protein response and survival duration of patients with pancreatic cancer. Cancer 1995 75:2077-82.

16. Ishii H, Okada S, Nose H, Yoshimori M, Aoki K, Okusaka T: Prognostic factors in patients with advanced pancreatic cancer treated with systemic chemotherapy. Pancreas 1996, | 2:267-7|.

17. Kau SY, Shyr YM, Su CH, Wu CW, Lui WY: Diagnostic and prognostic values of CA 19-9 and CEA in periampullary cancers. J Am Coll Surg 1999, 1 88:415-20.

18. Terwee CB, Nieveen Van Dijkum El, Gouma DJ, Bakkevold KE, Klinkenbij JH, Wade TP, van Wagensveld BA, Wong A, Meulen JH van der: Pooling of prognostic studies in cancer of the pancreatic head and periampullary region: the Triple-P study. Triple-P study group. EurJ Surg 2000, 166:706-12.
19. Ikeda M, Okada S, Tokuuye K, Ueno H, Okusaka T: Prognostic factors in patients with locally advanced pancreatic carcinoma receiving chemoradiotherapy. Cancer 200I, $91: 490-5$.

20. Saad ED, Machado MC, Wajsbrot D, Abramoff R, Hoff PM, Tabacof J Katz A, Simon SD, Gansl RC: Pretreatment CA 19-9 level as a prognostic factor in patients with advanced pancreatic cancer treated with gemcitabine. Int J Gastrointest Cancer 2002, 32:35-4I

2I. Engelken FJ, Bettschart V, Rahman MQ, Parks RW, Garden OJ: Prognostic factors in the palliation of pancreatic cancer. Eur J Surg Oncol 2003, 29:368-73.

22. Watanabe I, Sasaki S, Konishi M, Nakagohri T, Inoue K, Oda T, Kinoshita $\mathrm{T}$ : Onset symptoms and tumor locations as prognostic factors of pancreatic cancer. Pancreas 2004, 28: 160-5.

23. Sezgin C, Karabulut B, Uslu R, Sanli UA, Goksel G, Yuzer Y, Goker E: Gemcitabine treatment in patients with inoperable locally advanced/metastatic pancreatic cancer and prognostic factors. Scand / Gastroenterol 2005, 40: | 486-92.

24. Krishnan S, Rana V, Janjan NA, Abbruzzese JL, Gould MS, Das P, Delclos ME, Palla S, Guha S, Varadhachary G, Evans DB, Wolff RA, Crane $\mathrm{CH}$ : Prognostic factors in patients with unresectable locally advanced pancreatic adenocarcinoma treated with chemoradiation. Cancer 2006, 107:2589-96.

25. Maréchal R, Demols A, Gay F, De Maertelaere V, Arvanitaki M, Hendlisz A, Van Laethem JL: Prognostic factors and prognostic index for chemonaïve and gemcitabine-refractory patients with advanced pancreatic cancer. Oncology 2007, 73:4I-5I.

26. Park JK, Yoon YB, Kim YT, Ryu JK, Yoon WJ, Lee SH: Survival and prognostic factors of unresectable pancreatic cancer. J Clin Gastroenterol 2008, 42:86-9I.

27. Howe JR, Conlon KC: The molecular genetics of pancreatic cancer. Surg Oncol 1997, 6:1-18.

28. Papadoniou N, Kosmas C, Gennatas K, Polyzos A, Mouratidou D, Skopelitis E, Tzivras M, Sougioultzis S, Papastratis G, Karatzas G, Papalambros E, Tsavaris N: Prognostic factors in patients with locally advanced (unresectable) or metastatic pancreatic adenocarcinoma: a retrospective analysis. Anticancer Res 2008 , 28:543-9.

29. Kloppel G, Solcia E, Longnecker DS, Capella C, Sobin LH: Histological Typing of Tumours of the Exocrine Pancreas. WHO International Histological Classification of Tumours 2nd edition. Berlin, Springer-Verlag; 1996.

30. Sobin LH, Wittekind Ch, eds: UICC TNM Classification of Malignant Tumors 5th edition. New York, John Wiley \& Sons, Inc; 1997.

31. Weger AR, Mikuz G, Askensten U, Auer GU, Schwab G, Glaser KS: Methodological aspects of DNA image cytometry in formalin-fixed paraffin-embedded material from pancreatic adenocarcinoma. Pathol Res Pract 1989, 185:752-4.

32. Böttger TC, Störkel S, Wellek S, Stöckle M, Junginger T: Factors influencing survival after resection of pancreatic cancer. A DNA analysis and a histomorphologic study. Cancer 1994 73:63-73.

33. Yeo CJ, Cameron JL, Lillemoe KD, Sitzmann JV, Hruban RH, Goodman SN, Dooley WC, Coleman J, Pitt HA: Pancreaticoduodenectomy for cancer of the head of the pancreas. 201 patients. Ann Surg 1995, 221:721-733

34. Porschen R, Remy U, Bevers G, Schauseil S, Hengels KJ, Borchard F: Prognostic significance of DNA ploidy in adenocarcinoma of the pancreas. A flow cytometric study of paraffin-embedded specimens. Cancer 1993, 71:3846-50.

35. Alanen KA, Joensuu $H$, Klemi PJ, Nevalainen TG: Clinical significance of nuclear DNA content in pancreatic carcinoma. Journal of Pathology 1990, 160:313-320.

36. Yoshimura T, Manabe T, Imamura T, Imanishi K, Ohshio G, Yamabe $\mathrm{H}$, Kitamura O, Matsumoto M, Ogasahara K, Takasan H, et al:: Flow cytometric analysis of nuclear DNA content of duct cell carcinoma of the pancreas. Cancer 1992, 70:1069-74.

37. Schlichting E, Clausen OPF, Hanssen AS, Buanes TA: Ploidy and survival in respectable pancreatic cancers. Eur J Surg 1993, 159:229-233.

38. Rugge M, Sonego F, Sessa F, Leandro G, Capella C, Sperti C, Pasquali C, Di Mario F, Pedrazzoli S, Ninfo V: Nuclear DNA content and pathology in radically treated pancreatic carcinoma. The prognostic significance of DNA ploidy, histology and nuclear grade. Cancer 1996, 77:459-66. 
39. He YC, Qiao JG, Cao J, Chen JW: Relationship between nuclear morphometry, DNA content and respectability of pancreatic cancer. World J Gastroenterol 2003, 9:1863-65.

40. Baisch H, Klöppel G, Reinke B: DNA ploidy and cell-cycle analysis in pancreatic and ampullary carcinoma: flow cytometric study of formalin-fixed paraffin-embedded tissue. Virchows Arch A Pathol Anat Histopathol 1990, 4I 7: I45-50.

4I. Herrera MF, van Heerden JA, Katzmann JA, Weiland LH, Nagorney DM, Ilstrup D: Evaluation of DNA nuclear pattern as a prognostic determinant in resected pancreatic ductal adenocarcinoma. Ann Surg 1992, 215:120-4.

42. Stoecklein NH, Luebke AM, Erbersdobler A, Knoefel WT, Schraut W, Verde PE, Stern F, Scheunemann P, Peiper M, Eisenberger CF, Izbicki JR, Klein CA, Hosch SB: Copy number of chromosome 17 but not HER2 amplification predicts clinical outcome of patients with pancreatic ductal adenocarcinoma. J Clin Oncol 2004, I:4737-45. Erratum in: J Clin Oncol 2005, 23:248

43. Berczi C, Bocsi J, Lapis K, Balázs G: Relationship between the survival and the clinicopathological parameters of the patients with tumors in the pancreatic head region. Acta Chir Hung 1999, 38:235-41.

\section{Pre-publication history}

The pre-publication history for this paper can be accessed here:

http://www.biomedcentral.com/1471-2407/9/264/pre pub

Publish with Bio Med Central and every scientist can read your work free of charge

"BioMed Central will be the most significant development for disseminating the results of biomedical research in our lifetime. "

Sir Paul Nurse, Cancer Research UK

Your research papers will be:

- available free of charge to the entire biomedical community

- peer reviewed and published immediately upon acceptance

- cited in PubMed and archived on PubMed Central

- yours - you keep the copyright

Submit your manuscript here:

http://www.biomedcentral.com/info/publishing_adv.asp 